\title{
Trabalho colaborativo entre os professores do ensino regular e da educação especial
}

\author{
Collaborative work between teachers of the regular education and special \\ education \\ Trabajo colaborativo entre los profesores de enseñanza regular y la \\ educación especial
}

\author{
* João Carlos Vieira Casal \\ Professor mestre no Instituto Superior de Ciências Educativas, Odivelas, Portugal. \\ jcasal_isce@hotmail.com

\section{${ }^{* *}$ Francisca Maria Rochas Almas Fragoso} \\ Professora mestre no Instituto Superior de Ciências Educativas, Odivelas, Portugal. \\ franciscafragoso@iol.pt
}

Recebido em 29 de abril de 2017

Aprovado em 14 de abril de 2019

Publicado em 05 de junho de 2019

\section{RESUMO}

Este estudo pretende conhecer como é que os professores de educação especial e do ensino regular cooperam entre si. Portanto, pretende-se analisar as expectativas que têm uns dos outros, que dificuldades encontram no trabalho colaborativo e quais são as suas práticas de cooperação. A metodologia baseou-se na realização de uma entrevista exploratória e de um questionário que foi aplicado a uma amostra de 20 professores de educação especial e a outra de 20 professores do ensino regular. A taxa de respostas foi de $50 \%$ e para analisar os resultados utilizou-se uma análise de conteúdo. De uma maneira geral o estudo conclui que os professores de educação especial e do ensino regular encontram utilidade nas atitudes de cooperação, mas devem explorar melhor as relações entre si. As dificuldades de cooperação estão relacionadas com os obstáculos colocados pela estrutura organizacional e com a comunicação entre profissionais, patente na perceção que os professores do ensino regular têm acerca dos colegas da educação especial.

Palavras-chave: Cooperação; Trabalho colaborativo; Educação Especial.

\section{ABSTRACT}

This study aims to know how special education teachers and regular education teachers cooperate. Thus, it is intended to analyse the expectation they have of each other, the difficulties they found in the collaborative work, and what their cooperation practices are. The methodology was based on an exploratory interview and a questionnaire that was 
applied to a sample of 20 special education teacher and to another of 20 teachers of regular education. The response rate was $50 \%$ and content analysis was used to analyse the results. The study allows concluding that teacher of special education and regular education find useful in cooperative attitudes. The difficulties of cooperation are related to the obstacles posed by the organisational structure and communication between professionals, evident in the perception that teachers of regular education have about their special education colleagues.

Keywords: Cooperation; Collaborative Work; Special Education.

\section{RESUMEN}

Este estudio pretende conocer cómo los profesores de educación especial y de la enseñanza regular cooperan entre sí. Por lo tanto, se pretende analizar las expectativas que tienen unos de otros, que dificultades encuentran en el trabajo colaborativo y cuáles son sus prácticas de cooperación. La metodología se basó en la realización de una entrevista exploratoria y de un cuestionario que se aplicó a una muestra de 20 profesores de educación especial y la otra de 20 profesores de enseñanza regular. La tasa de respuestas fue del $50 \%$ y para analizar los resultados se utilizó un análisis de contenido. De una manera general el estudio concluye que los profesores de educación especial y de la enseñanza regular encuentran utilidad en las actitudes de cooperación, pero deben explotar mejor las relaciones entre sí. Las dificultades de cooperación están relacionadas con los obstáculos planteados por la estructura organizacional y con la comunicación entre profesionales, patente en la percepción que los profesores de la enseñanza regular tienen acerca de los colegas de la educación especial.

Palabras clave: Cooperación; Trabajo colaborativo; Educación Especial.

\section{Introdução}

Em Portugal há uma tendência progressiva para a diminuição das fronteiras entre o ensino regular e a educação especial. Na última década, a educação especial reorganizouse como parte integrante do sistema educativo e as transformações operaram-se em termos da integração, normalização, reabilitação e inclusão, bem como da colaboração dos profissionais envolvidos. A educação especial centra-se na organização e transformação de variáveis educativas relacionadas com a prevenção e redução ou eliminação das deficiências na aprendizagem (SMITH \& NEISWORTH, 1975). Portanto, todos os esforços dos professores devem ser centrados na organização adequada da cooperação, nomeadamente na escola, na família e na comunidade. Resulta, então, a questão: Como é 
que os professores de educação especial e do ensino regular, concebem o seu trabalho em termos de cooperação?

A escola deve ser uma comunidade educativa, capaz de mobilizar atores sociais e grupos profissionais em torno de um projeto comum (NÓVOA, 1992). Nesta perspetiva, a escola é uma organização dependente do exterior, com energia própria onde os seus atores têm um certo grau de liberdade em que negociam e treinam novos papéis. Esta dinâmica também é comum ao professor de educação especial, que leva para a escola a planificação conjunta, encontros interdisciplinares e reuniões de caso. Deste modo, vão-se criando condições para a colaboração e partilha de responsabilidades, que levam à aproximação dos professores na resolução dos problemas da escola e da população com necessidades especiais. No entanto, esta forma de intervenção requer atenção, uma vez que os membros de uma organização raramente aceitam cooperar sem obter compensações (MERTON, 1967). Ao professor de educação especial é exigida uma boa capacidade de gestão, de relação e de negociação. Assim, a cooperação não é espontânea e definitiva, mas dependente de fatores pessoais e institucionais.

Neste artigo discutem-se as condições para que os professores da educação especial e do ensino regular participem na definição e na execução das melhores decisões educacionais face à escola e aos alunos com necessidades especiais. Estas condições relacionam-se com a maneira como a escola se organiza em termos de espaço, tempos, conhecimentos e grupos. De acordo com Hutmacher (1992), só se aprende a cooperar comunicando, i.e., cooperando em situações reais e não apenas através de cursos. Deste modo, interessa conhecer como é que os professores de educação especial e do ensino regular, concebem o seu trabalho em termos de cooperação, que significado atribuem a uma ação partilhada e com que objetivo a propõem. De uma forma mais específica, o que se pretende é conhecer as expectativas que os professores do ensino regular e de educação especial têm uns dos outros e as dificuldades que encontram no trabalho colaborativo, bem como identificar as suas práticas de cooperação.

Para além da introdução, o artigo encontra-se organizado em mais quatro partes. A segunda parte compreende uma revisão da literatura dos conceitos de cooperação e trabalho colaborativo. A terceira parte reporta-se à metodologia e a quarta à apresentação e discussão de resultados. Por último, apresentam as principais conclusões do estudo. 


\section{Cooperação e trabalho colaborativo entre os professores}

Lakatos \& Marconi (1987) define a cooperação como um tipo particular de processo social em que dois ou mais indivíduos ou grupos, atuam em conjunto para a realização de um objetivo comum. Um pré-requisito para qualquer espécie de cooperação é a existência de um objetivo comum, que responda às metas específicas das estruturas envolvidas, podendo os deficientes representar um objetivo comum para muitas pessoas (OCDE/CERI, 1985). Segundo Gisbert et al. (1986), a troca de conhecimentos entre profissionais pode contribuir para: a) a utilização de uma linguagem comum; b) maior confiança; c) uma relação de interdependência; d) uma participação e uma responsabilidade comum; e) uma comprovação das decisões educacionais; f) uma estrutura e uma organização em equipa; e g) um modelo de comunicação entre os intervenientes.

De um modo geral os professores dispõem, contrariamente a outras profissões, de pouco tempo e recursos para (auto)organizar a troca e o debate coletivo das práticas de ensino. No entanto é de referir que os professores também investem pouco nestas ações, esperando que as hierarquias tomem a iniciativa (HUTMACHER, 1992). Alguns autores indicam que as razões de mal-estar dos professores na sua profissão estão relacionadas com demasiada exigência, salários inadequados e baixo estatuto social, falta de reconhecimento e isolamento profissional, incerteza e sentimento de impotência para resolver muitos dos problemas da escola (GOMES, 1993).

Nóvoa (1992) refere alguns fatores que podem determinar a inovação nas escolas, nomeando em primeiro lugar, as relações quotidianas de cooperação, de partilha e de coordenação entre professores e alunos. Carvalho (1992) refere que o nível de interação entre os professores é muito mais elevado nas escolas que têm um bom clima. A colaboração entre docentes deve assentar na colaboração voluntária, na escolha pessoal, na igualdade relacional, na partilha de objetivos comuns e de responsabilidades nas tomadas de posição e nos resultados (CORREIA, 2008, citando COOK \& Friend, 1995).

Segundo Isidro (2008), citando Panizt (1999), o trabalho colaborativo tem origem no trabalho de professores ingleses, que explorando as maneiras de ajudar os alunos a dar respostas às tarefas da escola, fizeram com que estes tivessem um papel mais ativo na sua própria aprendizagem. O trabalho colaborativo tem vindo a emergir como estratégia de ensino-aprendizagem nas últimas décadas (MENDES, 2006) e pode ser entendido como 
uma rede de recursos ao dispor do professor do ensino regular, tendo em vista o sucesso escolar dos alunos com necessidades especiais (COOK \& FRIEND, 1995).

Lee e Shulman (2004) desenvolveram na Califórnia um projeto de investigação sobre práticas de professores em diferentes disciplinas curriculares (Project "Fostering a community of teachers as learners"), centrado no conceito de comunidade de professores enquanto "aprendentes", em que as dimensões da colaboração surgem associadas à melhoria do conhecimento profissional e da eficácia do desempenho docente (ROLDÃO, 2007). Recentemente Peterson (2006), defendeu que os programas de inclusão não podem ser bem-sucedidos em escolas públicas, se professores do ensino regular e da educação especial não estiverem capacitados para implementar programas de ensino colaborativo. Pesquisas realizadas por vários autores, apresentam resultados positivos sobre a colaboração entre a educação especial e a educação regular, que relatam melhorias dos alunos com necessidades educacionais especiais (RIPLEY, 1997; SALEND \& DUHANEY, 1999; ARGUELLES et al., 2000).

O trabalho colaborativo é um processo articulado, que permite melhorar os resultados. Uma cultura de colaboração representa um dos caminhos mais eficientes para o desenvolvimento da educação inclusiva, como preconizam Stainback \& Stainback (1999), citando Curtis \& Safranski (1991). Correia (2005) é ainda mais concreto ao defender expressamente que no âmbito da inclusão o professor titular de turma deve conciliar-se com o professor de educação especial e com os pais para que todos possam em colaboração desempenhar estratégias de promoção do sucesso escolar.

A criação de relações de colaboração é condição essencial para um desenvolvimento curricular eficaz e para o desenvolvimento profissional dos professores face às mudanças educativas (CORREIA, 2007). A colaboração e a colegialidade pressupõem, que o melhoramento do ensino é mais uma questão coletiva do que individual e que processos de análise, avaliação e experimentação em conjunto com os colegas são oportunidades de aperfeiçoamento dos professores (FULLAN \& HARGREAVES, 2001).

Existem evidências de que as escolas onde predominam culturas colaborativas são mais inclusivas. Estas escolas são também mais efetivas na resolução de problemas dos estudantes (DAMIANI, 2008). Zanata (2004) e Loiola (2005), indicam que o trabalho colaborativo entre docentes é um excelente espaço de aprendizagem, permitindo a identificação de suas forças, fraquezas, dúvidas e necessidades de reconstrução. 
A atividade docente é um trabalho de articulação com os alunos, em que os equilíbrios na aula são frágeis e singulares. No entanto, a atividade na aula ganha um curso de ação dinâmico e emergente que não é totalmente premeditado e que resultada da negociação e articulação (LESSARD, 2009). Portanto, há necessidade que a articulação funcional entre os professores titulares de turma e os professores de educação especial seja concretizada de modo rigoroso (SERRANO, 2005).

A cultura de colaboração deve ser entendida, em cada comunidade escolar, como uma atitude dos docentes e discentes de entreajuda, confiança e respeito mútuo, que incentiva estratégias e a formulação de respostas adequadas às necessidades (CORREIA, 2003). Segundo Roldão (2007), o trabalho colaborativo parece merecer uma concordância generalizada entre professores e investigadores. No entanto, apesar de serem amplamente reconhecidas as potencialidades da colaboração entre os professores, esta não deixa de apresentar problemas.

\section{Metodologia}

Como foi referido anteriormente, este estudo pretende conhecer como é que os professores de educação especial e do ensino regular encaram a cooperação entre eles e que significado Ihe atribuem. Portanto, este objetivo geral encerra os seguintes objetivos específicos:

- Conhecer as expectativas e motivações que os professores do ensino regular e da educação especial têm uns dos outros acerca da cooperação;

- Conhecer as formas e a frequência das ações de cooperação entre os professores do ensino regular e da educação especial;

- Compreender quais as principais dificuldades que esses professores encontram no trabalho colaborativo.

- Conhecer a utilidade que encontram na cooperação e no trabalho colaborativo em termos do quotidiano educativo.

Tendo em conta esses objetivos, o design da investigação baseou-se na realização de entrevistas exploratórias e de um questionário a professores do ensino regular e de educação especial. Para a realização das entrevistas foi organizado um guião adaptado às populações do estudo, em que se procurou aferir da pertinência da cooperação na relação entre o professor educação especial e o professor da classe regular. $O$ tratamento das 
entrevistas foi realizado de forma a identificar os pontos críticos, relativamente à problemática da cooperação e os seus efeitos na realidade pedagógica.

Depois de realizadas e analisadas as entrevistas, procedeu-se à elaboração de um questionário com base nos resultados das entrevistas no questionário da Unidade de Ciências da Educação da Faculdade de Motricidade Humana da Universdade de Lisboa. $O$ questionário é composto por oito perguntas seis das quais abertas, e duas questões fechadas. À sua primeira formulação foi realizado um pré-teste a seis professores, após o qual se obteve uma versão final que foi analisada por um especialista de Ciências da Educação e de Investigação Educacional.

Uma vez concluída a versão final, procedeu-se à sua aplicação a uma amostra de quarenta professores, dos quais vinte são de educação especial e vinte são do ensino regular. A taxa de respostas foi de $50 \%$, i.e., da amostra inicial de quarenta professores, responderam vinte professores, sendo dez da educação especial com ou sem especialização, e dez professores do ensino regular a trabalhar no primeiro ciclo do ensino básico.

Recebidos os questionários, passou-se à fase de análise de dados para posterior tratamento, através da análise de conteúdo por categorias. Começou-se por fazer a inventariação dos temas por categorias e procurou-se identificar as unidades de significação de cada uma das categorias. Para o tratamento das questões do questionário elaborou-se uma grelha de análise, onde se registaram as frequências. As categorias consideradas para a análise do questionário foram as seguintes: Finalidades da Cooperação - que diz respeito aos objetivos finais que os professores encontram como resultado dum trabalho de cooperação; Motivação para a Cooperação - respostas que permitem identificar as razões pessoais e institucionais que levam os professores a cooperar; Frequências/Formas de Cooperação - inclui as respostas que ajudam a compreender as vivências de cooperação que os professores experimentam; Dificuldades na Cooperação - inclui as respostas que fornecem informações acerca dos principais obstáculos que os professores encontram para desenvolver um trabalho de cooperação, referenciando os obstáculos relacionados com o professor e com aspetos organizacionais; Sugestão para a Cooperação - aglutina os contributos que os professores podem dar para que o trabalho de cooperação seja facilitado nas escolas; Intervenientes na Cooperação - esta categoria tenta analisar o papel e a importância dos vários profissionais 
num trabalho de equipa; Responsabilidade dos Professores Regular/Especial na Cooperação - esta categoria tenta medir o que cada um dos professores espera do outro, ou seja, as expectativas com que partem para a cooperação; e Relato de Experiências tenta-se aqui agrupar as respostas que permitem aferir a conceção que os professores têm da cooperação.

\section{Resultados e discussão}

No Quadro 1 e no Quadro 2 apresenta-se a avaliação de categorias de cooperação pelos professores de educação especial e pelos professores do ensino regular, respetivamente. Os professores da educação especial entendem a finalidade da cooperação relacionada com a avaliação educacional (8), definição das estratégias de ação (8) e melhoria dos resultados de ensino e aprendizagem (8). Com menos frequência, também é referida a troca de conhecimentos (6). Em relação à motivação para a cooperação, a maior incidência de respostas (11) refere-se a fatores relacionados com a intervenção educacional. Portanto, os professores de educação especial encontram-se motivados para a cooperação e procuram melhorar os meios e as estratégias de intervenção. O mesmo se verifica na avaliação (10), que se for partilhada pode levar a um melhor conhecimento da criança. Em último lugar aparecem fatores de ordem pessoal (7). No que se refere à finalidade de cooperação, os professores do ensino regular referem que devem receber apoio do professor de educação especial (9), e que este deve dar apoio direto à criança. Em relação à categoria motivação para a cooperação, as respostas destes profissionais com maior incidência (14), são a existência de crianças com necessidades educativas específicas na sala de aula, as necessidades em termos de conhecimentos e de estratégias de intervenção (8), e o número de alunos a apoiar individualmente (7). Tal como Gisbert et al. (1986) referem, a troca de conhecimentos entre profissionais é bastante interessante a vários níveis e o nível de interação, de cooperação e de apoio mútuo influência de forma decisiva o bom funcionamento da escola (CARVALHO, 1992).

Em termos da frequência e formas de cooperação, os professores de educação especial (10) referem ter tido experiências de cooperação com o professor do regular, sobretudo ao nível da avaliação da criança (7) e da programação (3). Nas dificuldades na cooperação, a perceção que os professores do ensino regular têm dos professores da educação especial surge como o principal obstáculo (10). A seguir aparecem as dificuldades relacionadas com a organização do tempo na escola (8). Também, é referido 
a escassez de recursos (7), devido ao número reduzido de professores de educação especial. As respostas dos professores do ensino regular confirmam a existência de cooperação. Quanto às formas de cooperação, referem-se também à programação do trabalho para o aluno (5) e ao atendimento das necessidades educativas especiais. Em termos das dificuldades sentidas na cooperação, a organização do tempo na escola surge em primeiro lugar (9), logo seguida das dificuldades inerentes ao tipo de apoio que o professor de educação especial presta na escola (8). De fato os professores dispõem de pouco tempo e recursos e por conseguinte investem pouco em ações de cooperação (HUTMACHER, 1992). No entanto, o trabalho colaborativo tem-se tornado cada vez mais frequente como estratégia de ensino-aprendizagem (MENDES, 2006).

Como sugestões para a cooperação, os professores de educação especial apresentam em primeiro lugar a organização de encontros de discussão e formação (11). Em segundo lugar (8), referem a necessidade de uma melhor organização do tempo na escola. Referem-se também à motivação (7), à componente afetivo-relacional (6) e ao reforço dos recursos da escola (6), como fatores que também podem contribuir para a cooperação. Os professores do ensino regular também referem, a necessidade da realização de encontros de reflexão e informação (10), o apelo ao trabalho em conjunto (9) e a necessidade (6) de outra organização do tempo, de mais motivação (6) e de mais recursos humanos (6).

Os professores de educação especial veem com grande espectativa a responsabilidade do professor de educação regular num trabalho de cooperação, ao nível da avaliação / programação (9), do apoio ao aluno (7) e na disponibilidade para um trabalho em conjunto (7). Por sua vez, os colegas do ensino regular referem as responsabilidades do professor de educação especial num trabalho de cooperação ao nível da avaliação e da programação (9), da orientação do trabalho que o professor da classe desenvolve com as crianças com necessidades especiais (6), e em último lugar o apoio direto ao aluno (4). A partilha de informação e de experiências deve ser reforçada numa cultura de colaboração, que não se deve limitar à dimensão docente, mas deve ser alargada a outros profissionais. Portanto, os professores devem relacionar-se e colaborar, sempre que possível, com outros profissionais, nomeadamente, psicólogos, médicos e técnicos de serviço social ou terapeutas (CORREIA, 2003). 
Para os professores da educação especial, as experiências de cooperação situam-se ao nível da utilização e ensaio de novas metodologias (5) e no apoio à integração de crianças com necessidades educativas na sala de aula (4). Estes profissionais consideramse os principais intervenientes no processo de cooperação e valorizam a sua participação na equipa de trabalho e a do professor do ensino regular. Aparecem também referidos os psicólogos, os assistentes sociais e os médicos, e com menos frequência o diretor da escola, os terapeutas e outros elementos da comunidade. Neste caso, os professores do ensino regular relataram experiências pouco significativas. No entanto, consideram-se parte integrante no processo de cooperação e referem como principais intervenientes no processo a equipe de trabalho multidisciplinar, onde mencionam o psicólogo, a técnica de serviço social, o professor de educação especial e o professor de educação física e a equipe de saúde escolar.

Quadro 1 - Avaliação de Categorias de Cooperação pelos Professores do Ensino Especial

\begin{tabular}{|c|c|c|c|}
\hline Categorias & Sub-Categorias & Exemplos & Freq \\
\hline \multirow{4}{*}{$\begin{array}{l}\text { Finalidade da } \\
\text { Cooperação }\end{array}$} & Avaliação & "Detectar os porquês da n.e.e." & 8 \\
\hline & Estratégias & $\begin{array}{c}\text { "Encontrar estratégias para ..., melhor } \\
\text { desenvolvimento da criança" }\end{array}$ & 8 \\
\hline & $\begin{array}{c}\text { Melhorar os resultados } \\
\text { do Ensino/ } \\
\text { Aprendizagem }\end{array}$ & $\begin{array}{l}\text { "Satisfação das necessidades educativas } \\
\text { da criança ... visando a integração" }\end{array}$ & 8 \\
\hline & $\begin{array}{c}\text { Troca de } \\
\text { Conhecimentos }\end{array}$ & "Troca de saberes teórico / prático .." & 6 \\
\hline \multirow{3}{*}{$\begin{array}{l}\text { Motivação para } \\
\text { a Cooperação }\end{array}$} & Avaliação & $\begin{array}{c}\text { "Pleno conhecimento da criança e do seu } \\
\text { ambiente familiar" }\end{array}$ & 10 \\
\hline & Factores Pessoais & $\begin{array}{c}\text { "Uma vocação grande para trabalhar em } \\
\text { equipa" }\end{array}$ & 7 \\
\hline & Factores Educacionais & "Procura das melhores estratégias" & 11 \\
\hline \multirow{5}{*}{$\begin{array}{l}\text { Frequência e } \\
\text { Formas de } \\
\text { Cooperação }\end{array}$} & Verifica-se às vezes & & 4 \\
\hline & $\begin{array}{l}\text { Verifica-se com } \\
\text { frequência }\end{array}$ & & 4 \\
\hline & Verifica-se muitas vezes & & 2 \\
\hline & Avaliação & "Avaliação da criança periodicamente" & 7 \\
\hline & Programação & $\begin{array}{l}\text { "Elaboração e análise do Plano de } \\
\text { Intervenção" }\end{array}$ & 3 \\
\hline \multirow[b]{3}{*}{$\begin{array}{l}\text { Dificuldades na } \\
\text { Cooperação }\end{array}$} & Organização do Tempo & "Horário compatível" & 8 \\
\hline & $\begin{array}{l}\text { Percepção do Professor } \\
\text { de Educação Especial }\end{array}$ & $\begin{array}{l}\text { "Falta de reconhecimento do trabalho do } \\
\text { Professor de Educação Especial" }\end{array}$ & 10 \\
\hline & Recursos & $\begin{array}{c}\text { "Pequeno número de Professores de } \\
\text { Educação Especial que existem face às } \\
\text { necessidades dos Professores do Ensino } \\
\text { Regular" }\end{array}$ & 7 \\
\hline \multirow{4}{*}{$\begin{array}{l}\text { Sugestões } \\
\text { para a } \\
\text { Cooperação }\end{array}$} & Encontros / Formação & $\begin{array}{l}\text { "Reuniões promovidas pelo próprio } \\
\text { Ministério da Educação" }\end{array}$ & 11 \\
\hline & Motivação & $\begin{array}{c}\text { "Maior empenho dos próprios colegas de } \\
\text { educação especial" }\end{array}$ & 7 \\
\hline & Trabalho em Conjunto & "Elaboração de propostas conjuntas..." & 7 \\
\hline & Organização do Tempo & $\begin{array}{c}\text { "Tempo para reflexão conjunta entre os } \\
\text { professores de educação especial / ensino } \\
\text { regular" }\end{array}$ & 8 \\
\hline
\end{tabular}




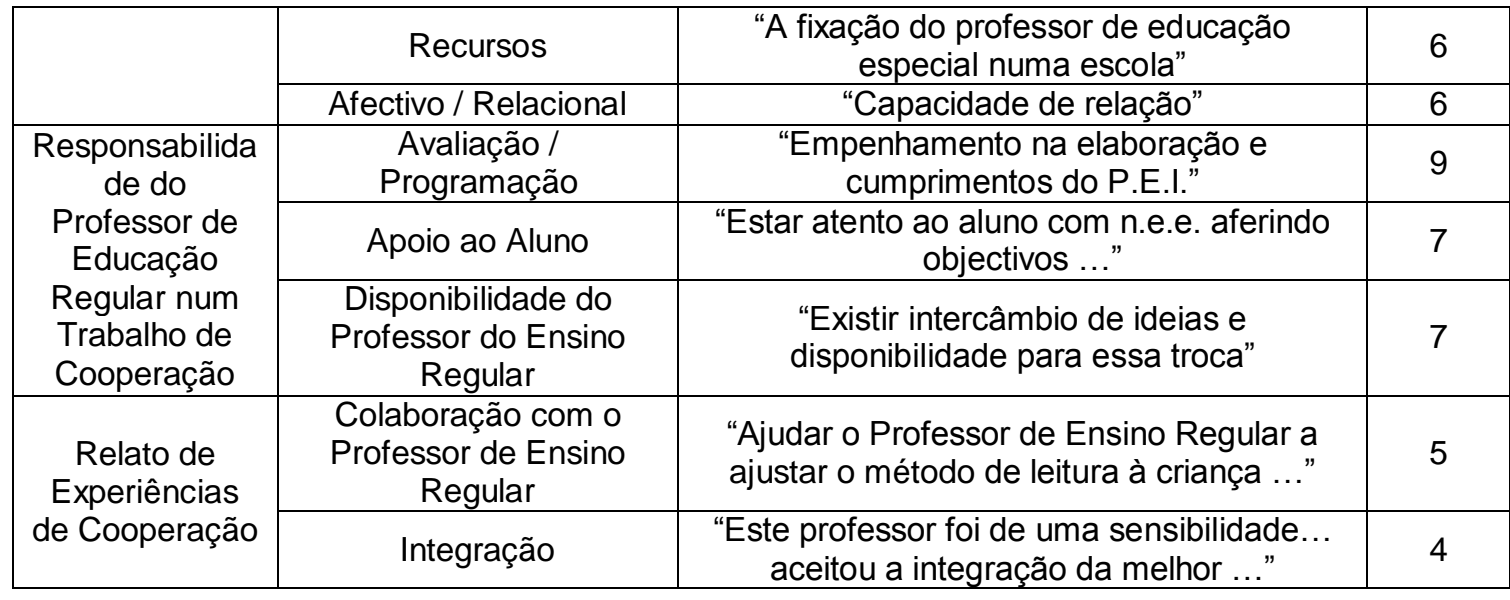

Quadro 2 - Avaliação de Categorias de Cooperação pelos Professores do Ensino Regular

\begin{tabular}{|c|c|c|c|}
\hline Categorias & Sub-Categorias & Exemplos & Freq \\
\hline \multirow{2}{*}{$\begin{array}{l}\text { Finalidade da } \\
\text { Cooperação }\end{array}$} & Apoio ao Professor & $\begin{array}{c}\text { "Ajudar o professor do ensino regular a } \\
\text { ultrapassar certos problemas" }\end{array}$ & 9 \\
\hline & Apoio à Criança & $\begin{array}{l}\text { "Melhorar o conhecimento da criança com } \\
\text { dificuldades" }\end{array}$ & 8 \\
\hline \multirow{4}{*}{$\begin{array}{l}\text { Motivação de } \\
\text { Cooperação }\end{array}$} & N.E.E. & $\begin{array}{l}\text { "Dificuldades de aprendizagem / } \\
\text { problemas de comportamento" }\end{array}$ & 14 \\
\hline & $\begin{array}{l}\text { Estratégias / } \\
\text { Intervenção }\end{array}$ & $\begin{array}{l}\text { "Estratégias de resolução para uma } \\
\text { melhor prática pedagógica" }\end{array}$ & 8 \\
\hline & Número de alunos & $\begin{array}{c}\text { "Necessidade de ensino individualizado a } \\
\text { algumas crianças, número elevado de } \\
\text { alunos por turma" }\end{array}$ & 7 \\
\hline & $\begin{array}{l}\text { Preocupações } \\
\text { ecológicas }\end{array}$ & "Problemas familiares" & 5 \\
\hline \multirow{6}{*}{$\begin{array}{l}\text { Frequência e } \\
\text { Formas de } \\
\text { Cooperação }\end{array}$} & $\begin{array}{c}\text { Verifica-se algumas } \\
\text { vezes }\end{array}$ & & 5 \\
\hline & $\begin{array}{l}\text { Verifica-se com } \\
\text { frequência }\end{array}$ & & 3 \\
\hline & Não existe cooperação & $\begin{array}{c}\text { "Não existe cooperação com professor de } \\
\text { educação especial" }\end{array}$ & 2 \\
\hline & Programação & $\begin{array}{c}\text { "Organização do Plano de Trabalho para o } \\
\text { aluno" }\end{array}$ & 5 \\
\hline & N.E.E. & "Dificuldades na aprendizagem" & 2 \\
\hline & & Não respondem & 3 \\
\hline \multirow{5}{*}{$\begin{array}{l}\text { Dificuldades na } \\
\text { Cooperação }\end{array}$} & Recursos & "Falta de técnicos especializados" & 5 \\
\hline & Organização do Tempo & "Poucos encontros regulares" & 9 \\
\hline & Tipo de Apoio Prestado & $\begin{array}{c}\text { "Poucos alunos que o Professor E.E. pode } \\
\text { apoiar" }\end{array}$ & 8 \\
\hline & Motivação & "Desinteresse do Professor E. Regular" & 6 \\
\hline & $\begin{array}{l}\text { Percepção do Prof. E. } \\
\text { E. }\end{array}$ & "Pensar que o Prof. E. E. faz milagres" & 6 \\
\hline \multirow{5}{*}{$\begin{array}{l}\text { Sugestões } \\
\text { para a } \\
\text { Cooperação }\end{array}$} & Recursos & "Haver maior número de professores" & 6 \\
\hline & Encontros / Formação & "Acções de Formação conjuntas" & 10 \\
\hline & Trabalho em Conjunto & "Planificação conjunta" & 9 \\
\hline & Organização do Tempo & "Debruçar-me mais sobre cada caso" & 6 \\
\hline & Motivação & "Interesse na cooperação" & 6 \\
\hline \multirow{2}{*}{$\begin{array}{l}\text { Responsabilida } \\
\text { des do } \\
\text { Professor de } \\
\text { Educação } \\
\text { Especial num }\end{array}$} & $\begin{array}{l}\text { Avaliação / } \\
\text { Programação }\end{array}$ & $\begin{array}{c}\text { "Fazer um estudo profundo da criança e } \\
\text { efectuar junto do Prof. E. R. um programa } \\
\text { apropriado" }\end{array}$ & 9 \\
\hline & $\begin{array}{l}\text { Orientação do Prof. Ed. } \\
\text { Regular }\end{array}$ & $\begin{array}{l}\text { "Orientar o Prof. Regular para dirigir } \\
\text { individualmente ... na sala de aula" }\end{array}$ & 6 \\
\hline
\end{tabular}


http://dx.doi.org/10.5902/1984686X26898

\begin{tabular}{|c|c|c|c|}
\hline $\begin{array}{c}\text { Trabalho de } \\
\text { Cooperação }\end{array}$ & Apoio ao Aluno & $\begin{array}{c}\text { "Tentar desbloquear as situações de } \\
\text { insucesso" }\end{array}$ & 4 \\
\hline \multirow{2}{*}{$\begin{array}{c}\text { Relato de } \\
\text { Experiências }\end{array}$} & Não teve experiências & $\begin{array}{c}\text { "Não vivi directamente qualquer } \\
\text { experiência, durante os 13 anos que } \\
\text { trabalhei" }\end{array}$ & 5 \\
\cline { 2 - 4 } & Troca de Informações & $\begin{array}{c}\text { "Depois da criança estar em apoio, tem } \\
\text { havido troca de impressões ...entre mim o } \\
\text { Prof. E. E." }\end{array}$ & 4 \\
\cline { 2 - 4 } & \multicolumn{2}{|c|}{$\begin{array}{c}\text { Não respondem } \\
1\end{array}$} \\
\hline
\end{tabular}

As opiniões expressas por ambos os profissionais relativas à cooperação são bastante coincidentes. Relativamente às motivações para a cooperação, no caso dos professores de educação especial, existem razões relacionadas com a melhoria da intervenção educacional. No caso dos professores do ensino regular encontram-se, sobretudo, razões relacionadas com o aumento dos seus conhecimentos e com o reforço dos meios humanos no apoio aos alunos com necessidades especiais. Ambos os grupos referem que já se verifica cooperação nas escolas, nomeadamente ao nível do planeamento e da intervenção junto da criança com necessidades especiais.

Para a criação de condições para a cooperação, as propostas/sugestões são globalmente coincidentes, salientando-se a necessidade de espaços de formação/reflexão e a implementação de processos que conduzam ao trabalho em conjunto. Ambos os professores referem a carência de organização nas escolas como oportunidade de criar condições para uma melhor comunicação entre os profissionais.

No trabalho em equipe, ambos os grupos não concebem a cooperação sem a sua própria participação. Uma diferença assinalável, é que os professores de educação especial valorizam os colegas do regular. O mesmo não se verifica em relação às escolhas dos professores do ensino regular, que escolhem primeiro como componente da equipe multidisciplinar o psicólogo e os técnicos de serviço social, e só depois os colegas de educação especial.

Os professores de educação especial esperam colaboração e disponibilidade dos colegas do ensino regular, para a avaliação e programação no apoio ao aluno na classe, e esperam poder colaborar na avaliação e programação, esperam do professor de educação especial orientação para o seu trabalho na classe. As práticas de cooperação são mais significativas no grupo de professores de educação especial. Os professores do ensino regular referem que as suas vivências de cooperação são pouco significativas e limitam-se à troca de informações com o professor de educação especial. 


\section{Conclusão}

Este estudo analisa como é que os professores do ensino especial e do ensino regular concebem o seu trabalho em termos de cooperação. Portanto, ensaiaram-se instrumentos e metodologias de trabalho que ajudaram a levantar pistas de reflexão sobre a problemática da cooperação entre os professores do ensino regular e do ensino especial.

De uma maneira geral o estudo concluiu que os profissionais de educação especial e do ensino regular encontram utilidade nas atitudes de cooperação, mas devem explorar melhor as relações entre si, para que surjam oportunidades de cooperação. As dificuldades que encontram na cooperação estão relacionadas com os obstáculos colocados pela estrutura organizacional e com a comunicação entre profissionais, patente na perceção que os professores do ensino regular têm acerca dos colegas da educação especial.

Seria importante que a escola pudesse implementar condições para que os professores tivessem mais espaços para a comunicação e para a troca de saberes. Podese potencializar os recursos criando-se grupos de trabalho para resolver problemas relacionados com a escola e particularmente grupos dinamizados pelo professor de educação especial direcionados para as crianças com necessidades especiais.

O problema da cooperação não é exclusivo da relação entre os professores do ensino regular e da educação especial, mas é extensível a todo o sistema de ensino/aprendizagem, e torna-se mais visível quando analisamos o funcionamento dos estabelecimentos de ensino. Sem pretender assumir generalizações a outros contextos, este estudo constitui um contributo para o conhecimento mais aprofundado das questões sobre a cooperação / trabalho colaborativo. Entre as suas principais limitações destaca-se a sua natureza e singularidade.

\section{Referências}

AGUELLES, M.E.; HUGHES, M.T.; SCHUMM, J.S. Co -Teaching: a different approach to inclusion. Principal Reston, v.79, no4, pp 48-50, 2000.

CARVALHO, L. M. Clima de escola e Estabilidade dos Professores. Lisboa: Educa, 1992.

COOK, L.; FRIEND, M. Co-Teaching: Guidelines for creating effective practices. Focus on Exceptional Children, №28, pp 1-16, 1995.

CORREIA, L.M. Inclusão e Necessidades Educativas Especiais: Um Guia para Educadores e Professores. 2 ${ }^{\underline{a}}$ Edição - Revista e ampliada. Porto: Porto Editora, 2008. 
CORREIA, Ana P.S.O. Contributos do Projecto Educativo para o trabalho colaborativo e reflexivo entre professores. Mestrado em Supervisão Pedagógica - Departamento Ciências de Educação da Universidade Aberta, 2007.

CORREIA, L.M. Inclusão e Necessidades Educativas Especiais: Um Guia para Educadores. Porto: Porto Editora, 2005.

CORREIA, L.M. Educação Especial e Inclusão. Porto: Colecção Educação especial, Porto Editora, 2003.

DAMIANI, M.F. Entendendo o trabalho colaborativo em educação e os seus benefícios. Educar, Curitiba, no 31, pp. 213-240, 2008. Editora UFPR.

FULLAN, M. \& HARGREAVES, A. Por que vale a pena lutar? O trabalho de equipa na escola. Porto: Porto Editora, 2001.

GISBERT, J. P. A. et al. Education Especial. Madrid: Cincel, 1986.

HUTMACHER, W. Escola em todos os estados: das políticas de sistemas às estratégias de estabelecimento, In: Hutmacher, W. Organizações Escolares em Análise, Lisboa: Publicações D. Qeixote, 1992. p. 45-76.

ISIDRO, P. O trabalho cooperativo na construção do saber matemático dos alunos. Dissertação de Mestrado em Educação Matemática: Universidade Aberta, 2008.

LAKATOS, E. M.; MARCONI, M. A. Sociologia Geral. S. Paulo: Editora Atlas S.A., 1987.

LESSARD, C. O Trabalho docente, a análise da actividade e o papel dos sujeitos. Sísifo: Revista de Ciências da Educação. Lisboa: n. 9, p. 119-127, 2009.

LOIOLA, L. J. S. L. Contribuições da pesquisa colaborativa e do saber prático contextualizado para uma proposta de formação continuada de professores de educação infantil. In: REUNIão ANUAL DA ANPED, 28., Caxambu, 2005. Anais... Caxambu, 2005. p. 1-16. CD-ROM.

MENDES, E. Colaboração entre ensino regular e especial: o caminho do desenvolvimento pessoal para a inclusão escolar. In MANZINI, J. - Inclusão e acessibilidades, 2006. p. 2941

Merton R. On sociological theories of the middle-range. In Merton, R. On Theoretical Sociology: Five essays old and new. New York: Free Press., 1967.

NÓVOA, A. et al. As Organizações Escolares em Análise. Lisboa: Publicações D. Quixote, 1992.

OCDE/CERI. Sistema de Educação Especial. Actas do Seminário Nacional. Lisboa: Projecto OCDE/CERI SNR, 1985.

PETERSON, P. Inclusão nos Estados Unidos: implementação e capacitação de professores. Revista Brasileira de Educação especial, v.12, №1, 2006.

RIPLEY, S. Colaboration between general and special education teachers. USA: ERIC Digest, 1997.

ROLDÃO, M.C. Função docente: natureza e construção do conhecimento profissional. Revista Brasileira de Educação, no4, pp. 94-103, Jan-Abril, 2007. 
SALEND, S.J.; DUHANEY, L.M.G. The impacts of inclusion on studens with and withaout disabilities and their educators. Remedial and Special Education, v.20, nำ, pp 114-126, 1999.

SERRANO, J. Percursos e práticas para uma escola inclusiva. Tese de Doutoramento. Universidade do Minho, 2005.

SMITH, R.M.; NEISWORTH, J.T. The exceptional child: a functional approach. McGraw-Hill, 1975. 434p..

STAINBACK, S.; STAINBACK, W. Inclusão: um guia para educadores. Porto Alegre: Artes Médicas Sul. Madrid. Editora Popular, S.A, 1999.

ZANATA, E.M. Práticas pedagógicas inclusivas para alunos surdos numa perspetiva colaborativa. Tese de Doutorado em Educação Especial, Programa de Pós-Graduação em Educação Especial, Universidade Federal de São Carlos, 2004.

\section{Correspondência}

João Carlos Vieira Casa - Instituto Superior de Ciências Educativas. R. Bento de Jesus Caraça 12. CEP: 2620-379. Ramada, Portugal.

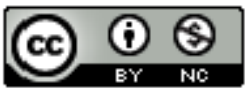

This work is licensed under a Creative Commons Attribution-NonCommercial 4.0 International (CC BY-NC 4.0) 